\title{
Regulation of the gtfBC and ftf genes of Streptococcus mutans in biofilms in response to $\mathrm{pH}$ and carbohydrate
}

\author{
Yunghua Li† and Robert A. Burne $\neq$ \\ Author for correspondence: Robert A. Burne. Tel: +1 352392 0011. Fax: +1 3523927357. \\ e-mail: rburne@dental.UFL.EDU
}

Center for Oral Biology and Department of Microbiology and Immunology, University of Rochester School of Medicine and Dentistry, 601 Elmwood Avenue, Rochester, NY 14642, USA

\begin{abstract}
Streptococcus mutans produces a number of extracellular sucrose-metabolizing enzymes that contribute to the ability of the organism to cause dental caries, including three glucosyltransferases, the products of the gtfB, gtfC and gtfD genes, and a fructosyltransferase, encoded by the $f t f$ gene. To better understand the regulation of the expression of these genes under environmental conditions that more closely mimic those in dental plaque, two strains of S. mutans harbouring fusions of the gtfBC (SMS102) and ftf (SMS101) promoters to a chloramphenicol acetyltransferase (CAT) gene were examined in biofilms formed in vitro. The strains were grown in a Rototorque biofilm reactor in a tryptone-yeast extract-sucrose medium. CAT specific activity in biofilm cells was measured at quasi-steady state or following additions of $25 \mathrm{mM}$ sucrose or glucose, with or without pH control. After approximately 10 generations of biofilm growth, the $f t f$ and gtfBC genes of $S$. mutans were found to be expressed at levels different from those reported for planktonic cells growing under otherwise similar conditions. The expression of these genes was induced by the addition of sucrose to the quasi-steady-state cultures. Expression of the gtfBC genes was influenced by environmental pH, since CAT specific activities in quasi-steady-state biofilms of strain SMS102 grown without pH control were twice those produced by cells grown with pH control. Moreover, addition of glucose to quasi-steady-state biofilms resulted in increased expression of the gtfBC-cat fusion, although the magnitude of the induction was less than that seen with sucrose. The effect of $\mathrm{pH}$ on $\mathrm{ftf}$ expression was negligible. A modest and transient induction of $\mathrm{ftf}$ was observed in biofilms pulsed with excess glucose and the kinetics and level of induction of $\mathrm{ftf}$ by excess carbohydrate were dependent on the $\mathrm{pH}$ of the biofilms. This study demonstrates that the type and amount of carbohydrate and the environmental pH have a major influence on transcription of the gtfBC and $f t f$ genes when the organisms are growing in biofilms, and provides evidence for previously undisclosed regulatory circuits for exopolysaccharide gene expression in S. mutans.
\end{abstract}

Keywords: exopolysaccharides, pathogenesis, glucans, dental caries, dental plaque

\section{INTRODUCTION}

Streptococcus mutans has been described as an 'obligate biofilm' organism (Burne, 1998b), and is considered to

† Present address: Faculty of Dentistry, University of Toronto, 124 Edward Street, Toronto, Ontario, Canada M5G 1 G6.

$\ddagger$ Present address: Department of Oral Biology, PO Box 100424, Gainesville, FL 32610-0424, USA.

Abbreviation: CAT, chloramphenicol acetyltransferase. be a principal aetiological agent of dental caries (Hamada \& Slade, 1980). The ability of $S$. mutans to initiate caries depends on several virulence-associated traits, including (i) initial adherence to the tooth through high-affinity adhesins, such as the SpaP protein, (ii) the ability to synthesize insoluble, extracellular polysaccharides that enhance accumulation and persistence of the organism on the tooth surfaces, (iii) a high capacity to catabolize carbohydrates and produce acids and (iv) the ability to grow and continue to metabolize 
carbohydrates at low $\mathrm{pH}$ (Burne, 1998a; Kuramitsu, 1993). Among these virulence attributes, the ability of $S$. mutans to produce extracellular polysaccharides from dietary carbohydrates has been demonstrated to significantly enhance its cariogenicity (Yamashita et al., 1993).

$S$. mutans synthesizes glucan polymers from sucrose via the actions of three secreted glucosyltransferases (GTFs), encoded by the gtfB, gtfC and gtfD genes (Kuramitsu, 1993). The gtfB and gtfC genes are in an operon-like arrangement and encode enzymes that produce mainly water-insoluble glucans, whereas the gtfD gene, which is not linked to the gtfBC locus, encodes an enzyme that catalyses the formation of a water-soluble glucan. It is the water-insoluble glucans made by GtfBC that play important roles in adhesion and accumulation of the organisms on the tooth surfaces, and in establishing the extracellular polysaccharide matrix that is responsible for the structural integrity of dental biofilms. These polysaccharides are also thought to provide the organisms with a unique microenvironment for their growth, metabolism and survival (Bowden \& Hamilton, 1998; Liljemark \& Bloomquist, 1996; Nakano \& Kuramitsu, 1992; Yamashita et al., 1993). S. mutans produces a single fructosyltransferase (FTF), the product of the $\mathrm{ftf}$ gene, which catalyses the synthesis of high-molecular-mass fructans from sucrose (Ebisu et al., 1975; Shiroza \& Kuramitsu, 1988). Fructans produced by $S$. mutans are believed to function primarily as extracellular storage compounds that can be metabolized during periods of nutrient deprivation (Burne et al., 1996).

A number of studies indicate that the expression of the genes for the exopolysaccharide-synthesizing enzymes of $S$. mutans is dependent on environmental conditions, including growth rate, $\mathrm{pH}$, carbon source, and whether the organisms are attached to the surfaces (Burne et al., 1997; Hudson \& Curtiss, 1990; Kiska \& Macrina, 1994; Wexler et al., 1993). Also, the use of gtf and $f t f$ gene fusion strains in a continuous-flow biofilm fermenter has shown that organisms growing in thicker, mature (7-d-old) biofilms have higher levels of expression of the gtfBC genes compared with cells grown in suspension or in thinner (2-d-old) biofilms (Burne et al., 1997; Hudson \& Curtiss, 1990; Kiska \& Macrina, 1994; Wexler et al., 1993). In contrast, $f t f$ was found to be dramatically down-regulated in $7 \mathrm{~d}$ biofilms compared with $2 \mathrm{~d}$ biofilms. The specific mechanisms governing regulation of exopolysaccharide synthesis in $S$. mutans biofilms have yet to be discovered. In this study, we test the hypothesis that $\mathrm{pH}$ or changes in carbohydrate source and concentration in biofilms influence expression of $g t f$ and $f t f$ in mature biofilms.

\section{METHODS}

Bacterial strains, growth media and biofilm reactor conditions. The bacterial strains utilized in this study were $S$. mutans harbouring $f t f-c a t$ (SMS101) or gtfBC-cat (SMS102) gene fusions. The construction of these strains and their genotypic stabilities are detailed elsewhere (Burne et al.,
1997; Hudson \& Curtiss, 1990; Wexler et al., 1993). The stability of the gene fusions in biofilms was again confirmed in this study by quantifying biofilm bacteria on selective and non-selective media, as previously detailed (Burne et al., 1997; Li et al., 2000). The strains were routinely maintained on brain heart infusion (BHI) agar (Difco) supplemented with $10 \mu \mathrm{g}$ erythromycin $\mathrm{ml}^{-1}$. For the development of biofilms, a tryptone-yeast extract base medium (TY; Burne et al., 1987) was diluted twofold and supplemented with $10 \mathrm{mM}$ sucrose and $10 \mu \mathrm{g}$ erythromycin $\mathrm{ml}^{-1}$, or with glucose $(5 \mathrm{mM})$ and $10 \mu \mathrm{g}$ erythromycin $\mathrm{ml}^{-1}$. In addition, the medium contained $50 \mathrm{mM}$ potassium phosphate buffer $(\mathrm{pH} 7 \cdot 8)$ for the experiments requiring $\mathrm{pH}$ control, or $90 \mathrm{mM} \mathrm{KCl}$ for those not requiring $\mathrm{pH}$ control, to ensure that the potassium ion concentration was similar in all cases. Mono-species biofilms were developed in a modified Rototorque biofilm reactor (Burne et al., 1997) with a working volume of 0.61 . The Rototorque is a stirred tank biofilm reactor that can be run in either batch or continuous mode. For this study, continuous culture was used by pumping medium at a fixed dilution rate and the biofilms were formed on slides that were inserted on the inner wall of the vessel. As configured for this study (Li et al., 2000), the Rototorque reactor allowed biofilm formation on 12 polystyrene slides, each with a mean exposed surface area of $31 \mathrm{~cm}^{2}$ for biofilm accumulation. After inoculation with $10 \mathrm{ml}$ of an overnight culture of $S$. mutans SMS101 or SMS102, medium was pumped into the vessel at a constant rate of $60 \mathrm{ml} \mathrm{h}^{-1}$ ('dilution rate', $D=0 \cdot 1 \mathrm{~h}^{-1}$ ). Samples were taken of quasi-steady-state biofilms and of biofilms pulsed with glucose or sucrose. Since bacteria in a biofilm are physiologically heterogeneous, a true steady state is not achieved, so the term quasi-steady state is used here instead. Cultures were designated to have reached quasi-steady state after the equivalent of 10 mean generation times using calculations detailed elsewhere (Burne \& Chen, 1998). The speed of the rotating inner drum of the Rototorque was kept constant at 75 r.p.m. and the temperature was maintained by immersion of the vessel in a $37^{\circ} \mathrm{C}$ circulating water bath.

Assessment of physical characteristics of $S$. mutans biofilms. Biofilm dry weights were determined by mechanically dissociating the biofilms from the slides, collecting the material by centrifugation, washing once with $\mathrm{dH}_{2} \mathrm{O}$, lyophilizing the sample and weighing. For measurement of total carbohydrate in biofilms, the lyophilized samples were resuspended in $5 \mathrm{ml}$ $\mathrm{dH}_{2} \mathrm{O}$ and the anthrone method (Dubois et al., 1956) was used to measure total carbohydrate using glucose as the standard. Bacterial viability in biofilms was estimated by direct microscopic enumeration and plate counts with cells prepared as follows. Biofilms were collected, washed once, and resuspended in $5 \mathrm{ml}$ of reduced transport fluid (Loesche \& Syed, 1973) at $\mathrm{pH} 7 \cdot 2$. The samples were then subjected to a gentle sonication at a setting of $150 \mathrm{~W}$ for $20 \mathrm{~s}$ to break bacterial chains, and the samples were split into two parts. The cell suspensions for viable cell counts were decimally diluted and directly inoculated by a spiral plating system (Autoplate model 3000; Spiral Biotech) onto BHI agar supplemented with $10 \mu \mathrm{g}$ erythromycin $\mathrm{ml}^{-1}$. The viable counts were made after the plates were cultivated at $37^{\circ} \mathrm{C}$ for $24 \mathrm{~h}$ in a $5 \% \mathrm{CO}_{2}$ aerobic atmosphere. Microscopic enumeration of bacteria was conducted as described by Koch (1994) using a Petroff-Hausser counting chamber. The ratio of viable cell counts to the counts obtained by visual enumeration was expressed as percentage viable cells. The formation and spatial distribution of biofilms on the surfaces were also assessed by using phase-contrast microscopy, as previously described (Burne et al., 1997; Li et al., 2000). 
In situ measurement of biofilm $\mathbf{p H}$. The $\mathrm{pH}$ of the biofilms was measured as previously detailed (Li et al., 2000) using a superminiature, Beetrode $\mathrm{pH}$ electrode (model MEPH3L; World Precision Instruments). Briefly, after the cultures reached quasi-steady state (Burne \& Chen, 1998), slides with biofilms were removed from the vessel and placed on end on a paper towel to allow excess medium to be absorbed from the end of the slides. The micro-reference electrode, which was connected through the Bee-Cal adapter and two cables to the $\mathrm{pH}$ probe and a standard $\mathrm{pH}$ meter, was positioned in the biofilm to be partially immersed in the biomass. In situ measurement of $\mathrm{pH}$ was conducted immediately by placing the tip of the $\mathrm{pH}$ probe into biofilms and a series of $\mathrm{pH}$ readings was recorded from a minimum of 30 different sites selected at random.

Carbohydrate pulsing and biofilm sampling. Quasi-steadystate biofilms, or biofilms which had been pulsed with either glucose or sucrose $(25 \mathrm{mM})$ immediately after initial biofilm sampling $\left(T_{0}\right)$, were used for measurements of chloramphenicol acetyltransferase (CAT) activity expressed from the $g t f$ or $\mathrm{ftf}$ promoters. Subsequently, the biofilms were sampled by removing three slides at 15,30 and $60 \mathrm{~min}$ after the carbohydrate pulse. The biofilms were mechanically dissociated from the slides by scraping with a sterile razor blade into $40 \mathrm{ml}$ ice-cold Tris/ $\mathrm{HCl}(10 \mathrm{mM}, \mathrm{pH} 7 \cdot 8)$ and were centrifuged at $8000 \mathrm{~g}$ for $10 \mathrm{~min}$ at $4{ }^{\circ} \mathrm{C}$. The cell pellets were washed twice and resuspended in $1 \mathrm{ml}$ of the same buffer for the preparation of cell-free lysates. The $\mathrm{pH}$ profiles in the liquid phase at each sampling time were recorded by measuring $\mathrm{pH}$ in $10 \mathrm{ml}$ of culture fluid.

Preparation of cell-free lysates and CAT assays. Cell-free lysates were prepared for the analysis of CAT activity as previously described (Chen et al., 1998). Briefly, the cell pellets were resuspended in $1 \mathrm{ml}$ Tris buffer in a $2 \mathrm{ml}$, screw-cap microcentrifuge tube (Sarstedt). One-third volume of prechilled $\left(-20^{\circ} \mathrm{C}\right)$ glass beads $(0 \cdot 2 \mathrm{~mm}$ mean diameter $)$ was added to the sample, and the cells were homogenized using a Bead Beater (Biospec Products) in four $30 \mathrm{~s}$ intervals, with cooling on ice in the intervals. The lysates were centrifuged at $12000 \mathrm{~g}$ at $4{ }^{\circ} \mathrm{C}$ for $15 \mathrm{~min}$ and the supernatant material was collected for CAT assays. Protein concentrations of the cellfree lysates were determined by the method of Bradford (1976) using a commercially available reagent (Bio-Rad). CAT activity was measured by a spectrophotometric method (Shaw, 1979) with use of the colorimetric substrate 5,5'-dithio-bisnitrobenzoic acid (DTNB; Boehringer Mannheim). All assays were performed in triplicate with internal standards containing all reagents except chloramphenicol to account for chloramphenicol-independent reduction of DTNB. One unit of CAT activity was defined as the amount of enzyme needed to catalyse the acetylation of $1 \mu \mathrm{mol}$ chloramphenicol $\mathrm{min}^{-1}$ $(\mathrm{mg} \text { protein })^{-1}$.

\section{RESULTS}

\section{Physical characteristics of $S$. mutans biofilms at quasi-steady state}

The biofilms at quasi-steady state were indistinguishable from biofilms of $S$. mutans and Streptococcus salivarius described previously (Burne et al., 1997; Li et al., 2000) (data not shown) and consisted of many microcolonies, aggregates and mats, with a considerable amount of extracellular polymer. As was observed with $S$. salivarius biofilm formation (Li et al., 2000), biofilms of
S. mutans formed more efficiently at low $\mathrm{pH}$ and the proportion of cells in the planktonic phase was far lower in cultures grown at lower $\mathrm{pH}$ values. In the cultures with buffered medium $(50 \mathrm{mM}$ potassium phosphate buffer, $\mathrm{pH} 7 \cdot 8$ ), the dry weight of the biofilms was $180 \mu \mathrm{g} \mathrm{cm}^{-2}$ (Table 1). When the medium was not buffered, the biomass of the biofilms was $50 \%$ greater than that of the biofilms formed in buffered medium. Analysis of total carbohydrates showed that the biofilms formed without $\mathrm{pH}$ control contained a higher percentage $(68 \%)$ of carbohydrates than those biofilms formed with $\mathrm{pH}$ control $(49 \%)$, and the total number of cells in the biofilms grown with $\mathrm{pH}$ control was about half that of biofilms formed without $\mathrm{pH}$ control. $S$. mutans SMS102 showed no significant differences from strain SMS101 in its growth characteristics, final yields or appearance in the biofilm reactor when grown under the same culture conditions (data not shown).

Similar to Rototorque biofilms of S. salivarius (Li et al., 2000), the $S$. mutans biofilms were heterogeneous and achieved thicknesses ranging from 10 to over $300 \mu \mathrm{m}$, and significant differences were noted between the $\mathrm{pH}$ values measured in the fluid phase and in the biofilms (Table 2). When $\mathrm{pH}$ control was imposed by buffering of the medium, the $\mathrm{pH}$ of the planktonic phase was near neutrality $(\mathrm{pH} 6 \cdot 68 \pm 0 \cdot 15)$, because the production of acid by the organisms always accompanies growth, and the $\mathrm{pH}$ measured within the biofilms was about 0.6 units lower. In the cultures without $\mathrm{pH}$ control, the in situ $\mathrm{pH}$ of the biofilms was slightly higher than the $\mathrm{pH}$ measured in the fluid phase, probably due to the cells acting as an effective buffer, and $0 \cdot 8 \mathrm{pH}$ units lower than in the biofilms formed with buffered medium. Therefore, the use of buffered medium was again an effective means to generate populations of biofilm cells exposed to a significant difference in $\mathrm{pH}$, and the effects of $\mathrm{pH}$ on exopolysaccharide gene expression could be reliably examined.

\section{CAT specific activity in biofilm cells at 'quasi-steady state' and following a carbohydrate pulse}

Biofilm cells were cultivated in a sucrose-containing medium to quasi-steady state at a dilution rate of $0 \cdot 1 \mathrm{~h}^{-1}$ for a minimum of a calculated 10 generations, i.e. $>69 \mathrm{~h}$ (Burne \& Chen, 1998). CAT activities were measured immediately before addition of sucrose to a final concentration of $25 \mathrm{mM}$ and at 15,30 and 60 min after the addition of sucrose (Table 3). Addition of sucrose in all cases resulted in a steady decline in the $\mathrm{pH}$ of the planktonic phase (Table 3). At quasi-steady state, CAT activity in the SMS101 ( $f t f-c a t)$ strain that was cultivated at the lower $\mathrm{pH}$ was always modestly lower than in biofilm cells grown with $\mathrm{pH}$ control, whereas SMS102 $(g t f B C-c a t)$ showed about a twofold increase of CAT when grown at lower $\mathrm{pH}$ values. Expression of the $\mathrm{ftf}$ and gtfBC genes was induced more than two- and fourfold, respectively, by the addition of sucrose to the steady-state cultures grown in buffered medium. An increase in CAT activity of about threefold in both 
Table 1. Physical characteristics of the biofilms of recombinant S. mutans SMS101 growing in sucrose-defined media at quasi-steady state

\begin{tabular}{|c|c|c|c|c|}
\hline $\begin{array}{l}\text { Culture } \\
\text { conditions }\end{array}$ & $\begin{array}{l}\text { Dry weight } \\
\left(\mu \mathrm{g} \mathrm{cm}^{-2}\right)\end{array}$ & $\begin{array}{l}10^{-8} \times \text { Direct } \\
\text { counts }\left(\mathrm{cm}^{-2}\right)^{*}\end{array}$ & $\begin{array}{c}10^{-8} \times \text { Viable } \\
\text { counts }\left(\mathrm{cm}^{-2}\right) \dagger\end{array}$ & $\begin{array}{c}\text { Total } \\
\text { carbohydrate }(\%)\end{array}$ \\
\hline pH controlł & $180 \pm 24$ & $2 \cdot 65 \pm 0.25$ & $1 \cdot 98 \pm 0 \cdot 28$ & 49 \\
\hline No pH controls & $277 \pm 40$ & $6 \cdot 24 \pm 0 \cdot 95$ & $3.92 \pm 0.50$ & 68 \\
\hline
\end{tabular}

* Direct counts were determined in a Petroff-Hauser counter as detailed in Methods.

† Viable counts determined by plating on BHI with $10 \mu$ g erythromycin $\mathrm{ml}^{-1}$.

$\ddagger$ Biofilms cultivated in media buffered with $50 \mathrm{mM}$ potassium phosphate buffer $(\mathrm{pH} 7 \cdot 8$ ).

\Biofilms cultivated in medium containing $90 \mathrm{mM} \mathrm{KCl}$.

Table 2. In situ pH profiles in the biofilms of recombinant S. mutans strains growing in sucrose-defined media at quasi-steady state

\begin{tabular}{|lcclcc|}
\hline \multirow{2}{*}{ Strain } & \multicolumn{2}{c}{ With $\mathrm{pH}$ control* } & & \multicolumn{2}{c|}{ Without $\mathrm{pH}$ control $\dagger$} \\
\cline { 2 - 3 } \cline { 5 - 6 } & $\mathrm{pH}$ in fluid phase & In situ $\mathrm{pH}$ & & $\mathrm{pH}$ in fluid phase & In situ $\mathrm{pH}$ \\
\cline { 5 - 6 } & $6 \cdot 68 \pm 0 \cdot 15$ & $6 \cdot 08 \pm 0 \cdot 12$ & & $5 \cdot 12 \pm 0 \cdot 25$ & $5 \cdot 32 \pm 0 \cdot 10$ \\
SMS101 & $6 \cdot 72 \pm 0 \cdot 12$ & $6 \cdot 11 \pm 0 \cdot 12$ & & $5 \cdot 14 \pm 0 \cdot 16$ & $5 \cdot 25 \pm 0 \cdot 14$ \\
\hline
\end{tabular}

* Biofilms cultivated in media buffered with $50 \mathrm{mM}$ potassium phosphate buffer ( $\mathrm{pH} 7 \cdot 8$ ).

† Biofilms cultivated in medium containing $90 \mathrm{mM} \mathrm{KCl}$.

Table 3. CAT specific activity of recombinant $S$. mutans strains growing in in vitro biofilms under sucrose limitation and following a $25 \mathrm{mM}$ sucrose pulse

Quasi-steady-state biofilms were formed for 10 generations with sucrose as the limiting carbohydrate prior to addition of sucrose to the vessel, as detailed in the text.

\begin{tabular}{|c|c|c|c|c|}
\hline \multirow{2}{*}{$\begin{array}{l}\text { Time (min) after } \\
\text { sucrose pulse }\end{array}$} & \multicolumn{2}{|c|}{ Strain SMS101 (ftf-cat) } & \multicolumn{2}{|c|}{ Strain SMS102 (gtfBC-cat) } \\
\hline & $\begin{array}{c}\mathrm{pH} \text { after } \\
\text { sucrose pulse }\end{array}$ & $\begin{array}{c}\text { CAT activity } \\
{\left[\mathrm{U}(\mathrm{mg} \text { protein })^{-1}\right]^{*}}\end{array}$ & $\begin{array}{c}\mathrm{pH} \text { after } \\
\text { sucrose pulse }\end{array}$ & $\begin{array}{c}\text { CAT activity } \\
{\left[\mathrm{U}(\mathrm{mg} \text { protein })^{-1}\right]^{*}}\end{array}$ \\
\hline \multicolumn{5}{|l|}{ With $\mathrm{pH}$ control $\dagger$} \\
\hline$T_{0}$ & $6 \cdot 68 \pm 0 \cdot 15$ & $0 \cdot 112 \pm 0 \cdot 08$ & $6 \cdot 72 \pm 0 \cdot 12$ & $0 \cdot 054 \pm 0 \cdot 03$ \\
\hline$T_{15}$ & $6 \cdot 34 \pm 0 \cdot 13$ & $0 \cdot 265 \pm 0 \cdot 10$ & $5 \cdot 76 \pm 0 \cdot 10$ & $0 \cdot 112 \pm 0 \cdot 04$ \\
\hline$T_{30}$ & $5 \cdot 87 \pm 0 \cdot 12$ & $0 \cdot 290 \pm 0 \cdot 08$ & $5 \cdot 21 \pm 0 \cdot 11$ & $0 \cdot 185 \pm 0 \cdot 06$ \\
\hline$T_{60}$ & $5 \cdot 51 \pm 0 \cdot 08$ & $0 \cdot 269 \pm 0 \cdot 05$ & $4 \cdot 98 \pm 0 \cdot 07$ & $0 \cdot 232 \pm 0 \cdot 12$ \\
\hline \multicolumn{5}{|c|}{ Without $\mathrm{pH}$ control $\neq$} \\
\hline$T_{0}$ & $5 \cdot 12 \pm 0 \cdot 25$ & $0 \cdot 091 \pm 0 \cdot 05$ & $5 \cdot 14 \pm 0 \cdot 16$ & $0 \cdot 106 \pm 0 \cdot 04$ \\
\hline$T_{15}$ & $4 \cdot 90 \pm 0 \cdot 33$ & $0 \cdot 298 \pm 0 \cdot 08$ & $4 \cdot 91 \pm 0 \cdot 14$ & $0 \cdot 224 \pm 0 \cdot 08$ \\
\hline$T_{30}$ & $4 \cdot 74 \pm 0 \cdot 28$ & $0 \cdot 262 \pm 0 \cdot 11$ & $4 \cdot 70 \pm 0 \cdot 04$ & $0 \cdot 318 \pm 0 \cdot 07$ \\
\hline$T_{60}$ & $4 \cdot 63 \pm 0 \cdot 35$ & $0 \cdot 183 \pm 0 \cdot 12$ & $4 \cdot 58 \pm 0 \cdot 06$ & $0 \cdot 382 \pm 0 \cdot 10$ \\
\hline
\end{tabular}

*Units are defined as $\mu \mathrm{mol}$ chloramphenicol acetylated $\min ^{-1}(\mathrm{mg} \text { protein })^{-1}$. The values shown are means from at least three separate Rototorque runs and all measurements were acquired in at least triplicate.

† Biofilms cultivated in media buffered with $50 \mathrm{mM}$ potassium phosphate buffer ( $\mathrm{pH} 7 \cdot 8$ ).

$\ddagger$ Biofilms cultivated in medium containing $90 \mathrm{mM} \mathrm{KCl}$. 
Table 4. CAT specific activity of recombinant $S$. mutans strains growing in in vitro biofilms with glucose limitation following a $25 \mathrm{mM}$ sucrose pulse

Biofilms were formed for 10 generations with sucrose as the limiting carbohydrate, then quasi-steady state was established under glucose-limiting conditions prior to addition of sucrose to the vessel, as detailed in the text.

\begin{tabular}{|c|c|c|c|c|}
\hline \multirow{2}{*}{$\begin{array}{l}\text { Time (min) after } \\
\text { sucrose pulse }\end{array}$} & \multicolumn{2}{|c|}{ Strain SMS101 $(f t f-c a t)$} & \multicolumn{2}{|c|}{ Strain SMS102 (gtfBC-cat) } \\
\hline & $\begin{array}{c}\mathrm{pH} \text { after } \\
\text { sucrose pulse }\end{array}$ & $\begin{array}{c}\text { CAT activity } \\
{\left[\mathrm{U}(\mathrm{mg} \text { protein })^{-1}\right]^{*}}\end{array}$ & $\begin{array}{c}\mathrm{pH} \text { after } \\
\text { sucrose pulse }\end{array}$ & $\begin{array}{c}\text { CAT activity } \\
{\left[\mathrm{U}(\mathrm{mg} \text { protein })^{-1}\right]^{*}}\end{array}$ \\
\hline \multicolumn{5}{|l|}{ With $\mathrm{pH}$ control $\uparrow$} \\
\hline$T_{0}$ & $6 \cdot 62 \pm 0 \cdot 12$ & $0 \cdot 088 \pm 0 \cdot 07$ & $6 \cdot 64 \pm 0 \cdot 15$ & $0 \cdot 042 \pm 0 \cdot 04$ \\
\hline$T_{15}$ & $6 \cdot 38 \pm 0 \cdot 18$ & $0 \cdot 226 \pm 0 \cdot 12$ & $6 \cdot 20 \pm 0 \cdot 22$ & $0 \cdot 176 \pm 0 \cdot 08$ \\
\hline$T_{30}$ & $5 \cdot 92 \pm 0 \cdot 13$ & $0 \cdot 287 \pm 0 \cdot 10$ & $5 \cdot 80 \pm 0 \cdot 21$ & $0 \cdot 258 \pm 0 \cdot 05$ \\
\hline$T_{60}$ & $5 \cdot 52 \pm 0 \cdot 24$ & $0 \cdot 254 \pm 0 \cdot 09$ & $5 \cdot 49 \pm 0 \cdot 18$ & $0 \cdot 295 \pm 0 \cdot 06$ \\
\hline \multicolumn{5}{|c|}{ Without $\mathrm{pH}$ control $\neq$} \\
\hline$T_{0}$ & $5 \cdot 08 \pm 0 \cdot 22$ & $0 \cdot 098 \pm 0 \cdot 07$ & $5 \cdot 11 \pm 0 \cdot 25$ & $0 \cdot 082 \pm 0 \cdot 03$ \\
\hline$T_{15}$ & $4 \cdot 89 \pm 0 \cdot 28$ & $0 \cdot 326 \pm 0 \cdot 14$ & $4 \cdot 92 \pm 0 \cdot 22$ & $0 \cdot 214 \pm 0 \cdot 07$ \\
\hline$T_{30}$ & $4 \cdot 82 \pm 0 \cdot 33$ & $0 \cdot 268 \pm 0 \cdot 12$ & $4 \cdot 80 \pm 0 \cdot 19$ & $0 \cdot 342 \pm 0 \cdot 12$ \\
\hline$T_{60}$ & $4 \cdot 72 \pm 0 \cdot 24$ & $0 \cdot 154 \pm 0 \cdot 12$ & $4 \cdot 79 \pm 0.23$ & $0 \cdot 395 \pm 0 \cdot 14$ \\
\hline
\end{tabular}

*Units are defined as $\mu \mathrm{mol}$ chloramphenicol acetylated $\min ^{-1}(\mathrm{mg} \text { protein })^{-1}$. The values shown are means from at least three separate Rototorque runs and all measurements were acquired in at least triplicate.

† Biofilms cultivated in media buffered with $50 \mathrm{mM}$ potassium phosphate buffer ( $\mathrm{pH} 7 \cdot 8$ ).

$\ddagger$ Biofilms cultivated in medium containing $90 \mathrm{mM} \mathrm{KCl}$.

Table 5. CAT specific activity of recombinant S. mutans strains growing in in vitro biofilms under sucrose limitation and following a $25 \mathrm{mM}$ glucose pulse

Quasi-steady-state biofilms were formed for 10 generations with sucrose as the limiting carbohydrate prior to addition of glucose to the vessel, as detailed in the text.

\begin{tabular}{|c|c|c|c|c|}
\hline \multirow{2}{*}{$\begin{array}{l}\text { Time (min) after } \\
\text { glucose pulse }\end{array}$} & \multicolumn{2}{|c|}{ Strain SMS101 $(f t f-c a t)$} & \multicolumn{2}{|c|}{ Strain SMS102 (gtfBC-cat) } \\
\hline & $\begin{array}{c}\text { pH after } \\
\text { glucose pulse }\end{array}$ & $\begin{array}{c}\text { CAT activity } \\
{\left[\mathrm{U}(\mathrm{mg} \text { protein })^{-1}\right]^{*}}\end{array}$ & $\begin{array}{c}\text { pH after } \\
\text { glucose pulse }\end{array}$ & $\begin{array}{c}\text { CAT activity } \\
{\left[\mathrm{U}(\mathrm{mg} \text { protein })^{-1}\right]^{*}}\end{array}$ \\
\hline \multicolumn{5}{|l|}{ With $\mathrm{pH}$ control $\dagger$} \\
\hline$T_{0}$ & $6 \cdot 70 \pm 0 \cdot 15$ & $0 \cdot 103 \pm 0 \cdot 03$ & $6 \cdot 65 \pm 0 \cdot 15$ & $0 \cdot 038 \pm 0 \cdot 03$ \\
\hline$T_{15}$ & $6 \cdot 20 \pm 0 \cdot 20$ & $0 \cdot 124 \pm 0 \cdot 05$ & $6 \cdot 20 \pm 0 \cdot 12$ & $0 \cdot 076 \pm 0 \cdot 04$ \\
\hline$T_{30}$ & $5 \cdot 80 \pm 0 \cdot 15$ & $0 \cdot 118 \pm 0 \cdot 04$ & $5 \cdot 75 \pm 0 \cdot 05$ & $0 \cdot 115 \pm 0 \cdot 04$ \\
\hline$T_{60}$ & $5 \cdot 50 \pm 0 \cdot 20$ & $0 \cdot 125 \pm 0 \cdot 06$ & $5 \cdot 50 \pm 0 \cdot 10$ & $0 \cdot 126 \pm 0 \cdot 06$ \\
\hline \multicolumn{5}{|c|}{ Without $\mathrm{pH}$ control $\neq$} \\
\hline$T_{0}$ & $5 \cdot 04 \pm 0 \cdot 20$ & $0 \cdot 084 \pm 0 \cdot 02$ & $5 \cdot 12 \pm 0 \cdot 18$ & $0 \cdot 114 \pm 0 \cdot 03$ \\
\hline$T_{15}$ & $4 \cdot 82 \pm 0 \cdot 25$ & $0 \cdot 188 \pm 0 \cdot 05$ & $4 \cdot 84 \pm 0 \cdot 22$ & $0 \cdot 167 \pm 0 \cdot 05$ \\
\hline$T_{30}$ & $4 \cdot 65 \pm 0 \cdot 26$ & $0 \cdot 175 \pm 0 \cdot 04$ & $4 \cdot 66 \pm 0 \cdot 20$ & $0 \cdot 198 \pm 0 \cdot 07$ \\
\hline$T_{60}$ & $4 \cdot 60 \pm 0 \cdot 24$ & $0 \cdot 116 \pm 0 \cdot 03$ & $4 \cdot 62 \pm 0 \cdot 21$ & $0 \cdot 224 \pm 0 \cdot 06$ \\
\hline
\end{tabular}

*Units are defined as $\mu \mathrm{mol}$ chloramphenicol acetylated $\min ^{-1}(\mathrm{mg} \text { protein })^{-1}$. The values shown are means from at least three separate Rototorque runs and all measurements were acquired in at least triplicate.

† Biofilms cultivated in media buffered with $50 \mathrm{mM}$ potassium phosphate buffer ( $\mathrm{pH} 7 \cdot 8$ ).

$\ddagger$ Biofilms cultivated in medium containing $90 \mathrm{mM} \mathrm{KCl}$.

SMS101 and 102 grown without $\mathrm{pH}$ control was seen after addition of sucrose. In all cases, there were differences in the kinetics of the induction between the $g t f$ and $f t f$ gene fusions and the induction pattern was different depending on whether the strains were cultivated with $\mathrm{pH}$ control or not. CAT activity in the gtf gene fusion strain increased steadily over a $1 \mathrm{~h}$ period following sucrose addition to biofilms grown in 
unbuffered medium. In contrast to the behaviour of SMS102, the induction of the $\mathrm{ftf}$ gene fusion in SMS101 by sucrose occurred within $15 \mathrm{~min}$ and was generally followed by a decline in CAT, the rate of which depended on the growth conditions. Notably, the rate of decline of CAT activity in SMS101 following a sucrose pulse was slower than that previously reported for strain SMS101 in biofilms (Burne et al., 1997), perhaps because of differences in the composition of the culture media or the time allowed for formation of biofilms in this study.

To determine whether the limiting growth carbohydrate in steady-state biofilms could affect the expression of $g t f$ or $f t f$, biofilms were formed in the presence of sucrose for 10 vessel volume changes, and then for an additional 10 vessel volume changes in the base medium containing $5 \mathrm{mM}$ glucose. When biofilms were formed in buffered medium, the level of CAT activity expressed by these strains at quasi-steady state, before addition of sucrose, was essentially the same as that observed for biofilms growing with sucrose as the limiting carbohydrate. After addition of $25 \mathrm{mM}$ sucrose to the glucose-limited biofilms, the patterns for induction of $f t f$ and $g t f B C$ genes were essentially similar to those patterns observed when quasi-steady-state, sucrose-limited biofilms were pulsed with sucrose (Table 4). Repeating this experimental strategy with glucose-limited biofilms formed in the absence of $\mathrm{pH}$ control (Table 4) yielded results essentially identical to those seen with biofilms formed in sucrose (Table 3). In all cases then, and in contrast to when cultures were exposed to excess sucrose, growth with sucrose as the limiting carbohydrate did not result in higher $\mathrm{gtf}$ or $\mathrm{ftf}$ expression when compared with glucose-limited biofilms. Moreover, growth in limiting concentrations of glucose did not change the ability of the strains to respond to induction by sucrose.

Finally, quasi-steady-state biofilms were formed in a sucrose-containing medium followed by a $25 \mathrm{mM}$ glucose pulse (Table 5). Interestingly, the CAT specific activity of strain SMS102 ( $g t f B C-c a t)$ increased about fourfold when glucose was added to biofilms growing in buffered medium. CAT specific activities of strain SMS102 also increased about twofold when glucose was added to biofilms growing without $\mathrm{pH}$ control. In the case of $S$. mutans SMS101 growing with $\mathrm{pH}$ control, there was little increase in the level of CAT activity after addition of glucose to the vessel. However, in SMS101 biofilms grown without $\mathrm{pH}$ control, transcription of $\mathrm{ftf}$ increased a little more than twofold after glucose addition, and then rapidly declined to baseline levels within $1 \mathrm{~h}$.

\section{DISCUSSION}

S. mutans in dental biofilms is subjected to a variety of different environmental conditions, most notably sudden changes in the type and amount of nutrients, accompanied by rapid and significant fluctuations in $\mathrm{pH}$ (Burne, 1998a; Carlsson, 1984). The ability of this organism to sense and respond to changes in the environment is crucial to its survival and cariogenicity (Bowden \& Hamilton, 1998). In a previous study, significant differences in expression of $g t f$ and $f t f$ were observed in mature biofilms versus relatively thinner biofilms or planktonic cells (Burne et al., 1997). One possible explanation for the differences in expression of the exopolysaccharide-synthesizing machinery of $S$. mutans in thicker biofilms is that, because of mass transport limitations, the $\mathrm{pH}$ and carbohydrate concentrations experienced by the organisms in the thick biofilms differ significantly from those to which planktonic cells or thinner biofilms are exposed. Results presented in this communication support the idea that expression of the $f t f$ and $g t f B C$ genes in biofilms is strongly influenced by carbohydrate availability, the type of carbohydrate, and the environmental $\mathrm{pH}$.

A number of new findings have emerged from this study. The first is that environmental $\mathrm{pH}$ clearly influences the expression of the gtfBC genes of $S$. mutans growing in biofilms. Biofilms grown without $\mathrm{pH}$ control, which had biofilm $\mathrm{pH}$ values of around $5 \cdot 3$, consistently had twofold more CAT activity expressed from the $g t f B C$ promoter than SMS102 cultivated with $\mathrm{pH}$ control. Moreover, following a carbohydrate pulse, the level of expression of $g t f B C$ in the biofilms without $\mathrm{pH}$ control was significantly higher than in biofilms with $\mathrm{pH}$ control. Since increased production of GtfBC would likely result in a greater proportion of carbohydrate being incorporated into biofilm polysaccharides, this observation is consistent with the finding that the biofilms formed at low $\mathrm{pH}$ were composed of a much greater percentage of carbohydrate than those formed at a more neutral $\mathrm{pH}$ value. Also, a previous study (Wexler et al., 1993) showed that when S. mutans was grown in steady-state continuous chemostat culture, lowering of the $\mathrm{pH}$ from 7 to 6 resulted in about a $50 \%$ increase in the expression of the $g t f B C$ genes. Interestingly, the level of expression of $g t f B C$ achieved by suspended populations at steady state or after a sucrose pulse (Wexler $e t$ al., 1993) was lower than the level of expression seen in biofilms at quasi-steady state or after sucrose induction in this study. Thus, one possible explanation for the enhanced $g t f B C$ expression in biofilms may be due to the relatively lower $\mathrm{pH}$ values achieved in biofilms (Table 2), compared to the continuous culture studies, or to the existence of low $\mathrm{pH}$ microenvironments in which gtf expression is markedly elevated. A second significant, and possibly related, finding is that $g t f B C$ expression in biofilms was induced by addition of excess glucose to the culture, albeit the level of induction was not as great as that seen with sucrose. There is no logical reason for glucose, which is not a substrate for Gtfs, to act as a specific inducer of $g t f B C$. Instead, it is more likely that the $g t f B C$ genes are induced in response to acidification of the biofilms or in response to the presence of an excess of a metabolizable carbohydrate. The latter could be signalled by directly sensing carbohydrate flow through the PTS or the glycolytic pathway, or could reflect a response to increased growth rate, although in continuous culture we found $g t f B C$ expression was inversely 
correlated with how fast the cells were growing (Wexler et al., 1993). Of note, there does not seem to be a hierarchy of control of expression of gtfBC by carbohydrate and $\mathrm{pH}$, since induction by excess carbohydrate occurs whether the cells are growing with or without $\mathrm{pH}$ control. Possibly, then, the effects of $\mathrm{pH}$ and carbohydrate are exerted through different pathways. Finally, we cannot exclude the idea that differences in phosphate concentrations in the buffered and unbuffered cultures also had an impact on the results.

Another important finding was that growth of the biofilms under quasi-steady-state conditions with glucose as the limiting carbohydrate did not result in downregulation of gtf or $f t f$ expression compared to cells growing with sucrose as the limiting carbohydrate. It has been suggested that sucrose is a specific inducer of exopolysaccharide-producing enzymes, but if that were the case, then one might expect higher levels of CAT activity expressed at $T_{0}$ in cells growing in sucrose (Tables 3 and 5) versus CAT activities at $T_{0}$ in biofilms being fed on glucose (Table 4), which was not the case. It could be that high levels of sucrose are required for induction, although this would not explain why both $\mathrm{ftf}$ and $g t f$ can be induced by addition of either glucose or sucrose. These findings emphasize the possibility that lowering of the $\mathrm{pH}$ following addition of carbohydrates or that an increase in the availability of carbohydrate, perhaps sensed via the PTS or glycolytic intermediates, are mechanisms by which $g t f$ and $f t f$ gene expression could be regulated. In fact, we now have preliminary evidence (unpublished) from continuous chemostat culture of these strains at different $\mathrm{pH}$ values, under carbohydrate-limiting and carbohydrate-excess conditions, that not only $\mathrm{pH}$, but the amount of carbohydrate available to cells is a factor that influences both $f t f$ and $g t f$ gene expression.

The expression pattern of $f t f$ is more complex than that of $g t f B C$. As with $g t f$, the expression levels of $f t f$ in quasi-steady-state biofilms are the same regardless of whether glucose or sucrose was the limiting carbohydrate. In contrast, $\mathrm{ftf}$ expression in the lower $\mathrm{pH}$ biofilms was not enhanced above that in biofilms formed with buffered medium. As seen previously with both suspended (Wexler et al., 1993) and adherent (Burne et al., 1997) populations of S. mutans, sucrose was an efficient inducer of $f t f$ gene expression. In this study, we found that induction by sucrose occurred regardless of whether the cells were growing at the lower or higher $\mathrm{pH}$ value, or whether the steady-state biofilms were formed with glucose or sucrose as the limiting carbohydrate. However, addition of glucose to quasi-steadystate biofilms had only a modest effect on induction of $\mathrm{ftf}$. In continuous chemostat culture, increasing the growth rate of strain SMS101, or lowering of the $\mathrm{pH}$ from 7 to 6, enhanced $f t f$ transcription (Wexler et al., 1993), so these factors were likely to have had an effect on $\mathrm{ftf}$ transcription after addition of excess carbohydrate. Still, in all cases, the responses of $f t f$ to added carbohydrate, i.e. the rate of induction and the subsequent decline in CAT activity, differed as a function of whether the culture medium was buffered or not. Thus, global factors regulating gene expression in relation to carbohydrate flow or $\mathrm{pH}$ may overlap with the regulatory networks that control $f t f$ transcription.

Another notable finding is that expression from the $g t f B C$ promoter in biofilms in this study was higher than that observed in cells grown in continuous chemostat culture (Wexler et al., 1993), although not as high as in mature (7 d) biofilms (Burne et al., 1997). For example, values in the chemostat were reported to range from 0.017 to $0.049 \mathrm{U}$ (mg protein) ${ }^{-1}$ under steady-state conditions, and levels after sucrose induction were as high as $0 \cdot 15 \mathrm{U}$ (mg protein $)^{-1}$. It can be inferred from the results obtained here that the existence of low $\mathrm{pH}$ microenvironments and perhaps the presence of extracellular storage polysaccharides that increase the amount of carbohydrate available to subpopulations of cells within the biofilm may account for the apparent stimulation of gtf expression in biofilms (Burne et al., 1997). Low growth rate microenvironments could also exist and impact $g t f B C$ expression. We also have noted that $f t f$ expression in mature $(7 \mathrm{~d})$ biofilms is almost completely repressed. Interestingly, the level of CAT expressed from the $f t f$ gene fusion in quasi-steady-state biofilms (Tables 3-5) was about one-third of that in suspended cells in steady-state continuous chemostat culture (Wexler et al., 1993). Also, following induction of $f t f$ in the chemostat using sucrose, levels of CAT peaked at about 0.45 U (Wexler et al., 1993), whereas the peak expression noted here was about $0 \cdot 33 \mathrm{U}$. So again, the trend is that $\mathrm{ftf}$ expression in biofilms is partially repressed compared with suspended populations. Recently, we have also found evidence that growth at $\mathrm{pH} 5$ leads to nearly complete repression of $f t f(C$. Browngardt \& R. A. Burne, unpublished), so low $\mathrm{pH}$ in the biofilms may account in part for lowered expression of $f t f$ in biofilms.

Clearly, $\mathrm{pH}$ and the source and amount of carbohydrate influence the transcription of the exopolysaccharide machinery of $S$. mutans in biofilms. However, a number of other factors could also account for altered $g t f$ and $f t f$ expression in mature biofilms. The first is that the availability of other nutrients and oxygen may be altered compared to young biofilms or planktonic cells. Goodman \& Gao (2000) have found that $g t f$ expression occurs at specific growth phases and have suggested a possible cell-density-dependent component regulating gtfBC, raising the possibility that intercellular signalling may be involved in regulating gtf expression. Although the results we have collected thus far do not fully support that quorum sensing is a regulator of exopolysaccharide synthesis in $S$. mutans, a luxS homologue is identifiable in the $S$. mutans chromosome, and peptide-mediated intercellular signalling is also established in S. mutans (Li et al., 2001). Therefore, the idea that exopolysaccharide production is regulated by quorum sensing mechanisms cannot yet be excluded. In summary, this study highlights the need for additional research with suspended and adherent oral streptococci to determine whether the changes in the expression 
patterns of genes of $S$. mutans growing in biofilms are restricted to spatially isolated subpopulations or to pathways that globally regulate biofilm gene expression in densely packed populations.

\section{ACKNOWLEDGEMENTS}

We would like to thank Dr Margaret Chen and Dr José Lemos for a critical evaluation of this manuscript. This work was supported by grant number DE12236 and DE13239 from the National Institute of Dental Research.

\section{REFERENCES}

Bowden, G. H. \& Hamilton, I. R. (1998). Survival of oral bacteria. Crit Rev Oral Biol Med 9, 54-85.

Bradford, M. M. (1976). A rapid and sensitive method for the quantitation of microgram quantities of protein utilizing the principle of protein-dye binding. Anal Biochem 72, 248-254.

Burne, R. A. (1998a). Oral streptococci: products of their environment. J Dent Res 77, 445-452.

Burne, R. A. (1998b). Regulation of gene expression in adherent populations of oral streptococci. In Microbial Pathogenesis: Current and Emerging Issues, pp. 55-70. Edited by D. J. LeBlanc, M. S. Lantz \& L. M. Switalski. Indianapolis, IN: Indiana University Press.

Burne, R. A. \& Chen, Y. M. (1998). The use of continuous flow bioreactors to explore gene expression and physiology of suspended and adherent populations of oral streptococci. Methods Cell Sci 20, 181-190.

Burne, R. A., Schilling, K., Bowen, W. H. \& Yasbin, R. E. (1987). Expression, purification, and characterization of an exo-beta-Dfructosidase of Streptococcus mutans. J Bacteriol 169, 4507-4517.

Burne, R. A., Chen, Y. M., Wexler, D. L., Kuramitsu, H. \& Bowen, W. H. (1996). Cariogenicity of Streptococcus mutans strains with defects in fructan metabolism assessed in a program-fed specificpathogen-free rat model. J Dent Res 75, 1572-1577.

Burne, R. A., Chen, Y. M. \& Penders, J. E. (1997). Analysis of gene expression in Streptococcus mutans in biofilms in vitro. Adv Dent Res 11, 100-109.

Carlsson, J. (1984). Regulation of sugar metabolism in relation to the 'feast-and famine' existence of plaque. In Cariology, pp. 205-211. Edited by B. Guggenheim. Basel: Karger.

Chen, Y. M., Weaver, C. A., Mendelsohn, D. R. \& Burne, R. A. (1998). Transcriptional regulation of the Streptococcus salivarius 57.I urease operon. J Bacteriol 180, 5769-5775.

Dubois, M., Gilles, K. A., Hamilton, J. K., Rebers, P. A. \& Smith, F. (1956). Colorimetric method for the determination of sugar and related substances. Anal Chem 28, 350-356.
Ebisu, S., Keijiro, K., Kotani, S. \& Misaka, A. (1975). Structural differences in the fructans elaborated by Streptococcus mutans and Strep. salivarius. J Biochem 78, 879-887.

Goodman, S. D. \& Gao, Q. (2000). Characterization of the gtfB and gtfC promoters from Streptococcus mutans GS-5. Plasmid 43, 85-98.

Hamada, S. \& Slade, H. D. (1980). Biology, immunology, and cariogenicity of Streptococcus mutans. Microbiol Rev 44, 331-384.

Hudson, M. C. \& Curtiss, R., III (1990). Regulation of expression of Streptococcus mutans genes important to virulence. Infect Immun 58, 464-470.

Kiska, D. L. \& Macrina, F. L. (1994). Genetic regulation of fructosyltransferase in Streptococcus mutans. Infect Immun 62, 1241-1251.

Koch, A. L. (1994). Growth measurement. In Methods for General and Molecular Bacteriology, pp. 249-276. Edited by P. Gerhardt, R. G. E. Murray, W. A. Wood \& N. R. Krieg. Washington, DC: American Society for Microbiology.

Kuramitsu, H. K. (1993). Virulence factors of mutans streptococci: role of molecular genetics. Crit Rev Oral Biol Med 4, 159-176.

Li, Y. H., Chen, Y. M. \& Burne, R. A. (2000). Regulation of urease gene expression by Streptococcus salivarius growing in biofilms. Environ Microbiol 2, 169-177.

Li, Y. H., Lau, P. C., Lee, J. H., Ellen, R. P. \& Cvitkovitch, D. G. (2001). Natural genetic transformation of Streptococcus mutans growing in biofilms. J Bacteriol 183, 897-908.

Liljemark, W. F. \& Bloomquist, C. (1996). Human oral microbial ecology and dental caries and periodontal diseases. Crit Rev Oral Biol Med 7, 180-198.

Loesche, W. J. \& Syed, S. A. (1973). The predominant cultivable flora of carious plaque and carious dentine. Caries Res 7, 201-216.

Nakano, Y. J. \& Kuramitsu, H. K. (1992). Mechanism of Streptococcus mutans glucosyltransferase: hybrid-enzyme analysis. $J$ Bacteriol 174, 5639-5646.

Shaw, W. V. (1979). Chloramphenicol acetyltransferase activity from chloramphenicol-resistant bacteria. Methods Enzymol 43, 737-755.

Shiroza, T. \& Kuramitsu, H. K. (1988). Sequence analysis of the Streptococcus mutans fructosyltransferase gene and flanking regions. J Bacteriol 170, 810-816.

Wexler, D. L., Hudson, M. C. \& Burne, R. A. (1993). Streptococcus mutans fructosyltransferase $(f t f)$ and glucosyltransferase $(g t f B C)$ operon fusion strains in continuous culture. Infect Immun 61, 1259-1267.

Yamashita, Y., Bowen, W. H., Burne, R. A. \& Kuramitsu, H. K. (1993). Role of the Streptococcus mutans gtf genes in caries induction in the specific-pathogen-free rat model. Infect Immun 61, 3811-3817.

Received 19 April 2001; revised 4 June 2001; accepted 8 June 2001 